\title{
Helicobacter pylori Positive
}

National Cancer Institute

\section{Source}

National Cancer Institute. Helicobacter pylori Positive. NCI Thesaurus. Code C160369.

An indication that Helicobacter pylori has been detected in a sample. 